W. Child - "Sensations, Natural Properties, and the Private Language Argument” - forthcoming in K. Cahill and T. Raleigh eds, Wittgenstein and Naturalism, Routledge.

\title{
Sensations, Natural Properties, and the Private Language Argument
}

\author{
William Child
}

I start with three questions about our concepts of conscious states. (1) How do I understand what it is for me to be in pain? (2) How do I understand what it is for someone else to be in pain? (3) Is the property of pain that I ascribe to others on the basis of what they say and do the same as the property I ascribe to myself without evidence?

Wittgenstein's response to those questions involves a general anti-platonism about properties or standards of similarity. What it is for one thing to be similar to another, or to have the same property as another, he thinks, is not dictated by reality itself; it depends on our classificatory practices and the standards of similarity they embody. It comes more naturally to us to classify things in some ways than others. But no property or standard of similarity is intrinsically or objectively more natural than any other: more natural simplicter. Wittgenstein's view stands in sharp opposition to the contemporary doctrine of natural properties. ${ }^{1}$ For the natural properties view holds precisely that there is an objective hierarchy of naturalness amongst properties, a hierarchy that does not depend in any way on our concepts or practices.

I want to explore the interaction between Wittgenstein's position about sensations and sensation language and his anti-platonism. Some anti-Wittgensteinian views in the philosophy of mind make essential appeal to the idea of natural properties. What are the prospects for such views? Do they pose a threat to a broadly Wittgensteinian position about sensations and sensation-language?

\section{Wittgenstein's position and the rejection of natural properties}

One way of answering the questions with which we started involves what we might call the model of introspection and identity. On this view the answers to questions 1 and 2 are, in the broadest outline, as follows:

1. I understand what it is for me to be in pain from the first-person case. (As Wittgenstein puts this view: 'it is only from my own case that I know what the word “pain” means'. ${ }^{2}$ ) I single out a kind of sensation on the basis of how it feels in the first-person case, and I associate the word 'pain' with sensations of that introspectively-identified kind.

2. I grasp what it is for someone else to be in pain by extension from the first-person case: what it is for someone else to be in pain is for her to be in the same kind of conscious state that I am in when I am in pain. (As Wittgenstein puts the view: 'if I suppose that someone else has a pain, then I am simply supposing that he has just the same as I have so often had'. $\left.{ }^{3}\right)^{4}$

\footnotetext{
1 Locus classicus: David Lewis, “New Work for a Theory of Universals,” Australasian Journal of Philosophy 61 (1983) and "Putnam’s Paradox,” Australasian Journal of Philosophy 62 (1984). For development and discussion see Theodore Sider, Writing the Book of the World (Oxford: Oxford University Press, 2011).

${ }^{2}$ Ludwig Wittgenstein, Philosophical Investigations 4th edn., ed. P. M. S. Hacker and Joachim Schulte, trans. G. E. M. Anscombe, P. M. S. Hacker and Joachim Schulte (Oxford: Blackwell, 2009), §293.

3 Wittgenstein, Philosophical Investigations, §350.

${ }^{4}$ We shall see later how, on this approach, an answer to question 3 falls naturally out of the answer to question 2.
} 
W. Child - "Sensations, Natural Properties, and the Private Language Argument” - forthcoming in K. Cahill and T. Raleigh eds, Wittgenstein and Naturalism, Routledge.

Wittgenstein famously argues against both parts of that account: the idea that we can single out the property of pain by introspective ostension in the first-person case; and the idea that we can understand the word in third-person ascriptions by appeal to the idea of another person's being in the same kind of state as me. At both points, his argument essentially depends on his general opposition to the metaphysics of natural properties.

Wittgenstein's opposition to stage 1 of the introspection-and-identity model is a central aspect of the private language sections of Philosophical Investigations. A crucial theme of those sections is that one cannot give meaning to a word for a kind of sensation by introspective ostension, in a way that does not rely on any links with behavior or external circumstances. That is the burden of Wittgenstein's discussion of the private sensation diarist in Philosophical Investigations §258. The point of that discussion, as I read it, is this. In order to give a meaning to a word, I must establish a standard of correctness for uses of the word: a standard that distinguishes between a correct and an incorrect application of the word. The private linguist thinks she can establish such a standard of correctness by concentrating her attention on the sensation she is having at a particular point and undertaking to use the word ' $S$ ' for all sensations of the same kind. But, Wittgenstein asks, what is it for something else to be the same kind of sensation as this one? There are indefinitely many different possible standards of similarity. And no one way of classifying sensations as similar or different is any better, or more correct, than any other. What it takes for one sensation to belong to the same kind as another is not determined by the nature of things; it has to be understood by reference to a humanly-created standard of similarity. But in order for there to be a humanly-created standard of similarity, there has to be a practice of classification; a technique of applying a word. ${ }^{5}$ And the private linguist, Wittgenstein argues, cannot establish a classificatory practice by a one-off act of introspective association.

Wittgenstein's argument depends on his general anti-platonist insistence that the world itself does not dictate what it takes for one thing to belong to the same kind as another. For suppose there is simply a fact of the matter, independent of our concepts and our practices of classification, about what it takes for one sensation to belong to the same kind as another. In that case, there will similarly be a practice-independent fact of the matter about whether the sensation the private linguist has today is the same kind of sensation as the one she had yesterday when she introduced her word ' $S$ '. So when the diarist attends introspectively to a particular sensation and says, "I shall use the word " $S$ " to refer to sensations of the same kind as this one', she will, pace Wittgenstein, thereby establish a standard of correctness for future applications of the word ' $\mathrm{S}$ '. Or so, at least, the propertynaturalist will argue.

We can trace a similar dialectic in connection with Wittgenstein's opposition to stage 2 of the introspection-and-identity model. Suppose that, contrary to the private language sections, I do understand the word 'pain', in the first instance, solely on the basis of my introspective awareness of my own pain. On the introspection-and-identity model, I then grasp what it is for someone else to be in pain by appeal to the principle that for someone else to be in pain is for her to be in the same kind of state that I am in when I am in pain.

Wittgenstein famously rejects that idea:

That gets us no further. It is as if I were to say, 'You surely know what "It's 5 o'clock here” means; so you also know what "It's 5 o'clock on the sun” means. It means simply that it is just the same time there as it is here when it is 5 o'clock.' - The explanation by means of sameness does not work here. For I know well enough that one can call 5 o'clock here and 5 o'clock there 'the same time', but I do not know in what cases one is to speak of its being the same time here and there.

\footnotetext{
${ }^{5}$ For the point about a technique, in this context, see Wittgenstein, Philosophical Investigations, §262.
} 
W. Child - "Sensations, Natural Properties, and the Private Language Argument” - forthcoming in K. Cahill and T. Raleigh eds, Wittgenstein and Naturalism, Routledge.

In exactly the same way, it is no explanation to say: the supposition that he has a pain is simply the supposition that he has the same as I. For what's surely clear to me is this part of the grammar: that one will say that the stove has the same experience as I if one says: it's in pain and I'm in pain. ${ }^{6}$

His point is this. The principle, 'for someone else to be in pain is for her to be in the same state that I am in when I am in pain', is true. But I cannot extract a conception of what it is for someone else to be in pain merely from the principle about sameness of state, by itself. For there are indefinitely many different possible states of $S$ that could count as S's being in the same state that I'm in when I feel pain. Appealing to the notion of sameness of state, then, is not by itself enough to specify what it takes for $\mathrm{S}$ to be in pain; I need some substantive understanding of what it takes for $S$ to be in the same state as me.

As before, Wittgenstein's position depends on his anti-platonism. For suppose there are natural properties. Then, it seems, we can appeal to sameness of property in explaining what it is for someone else to be in pain. For in that case the explanation, 'for $\mathrm{S}$ to be in pain is for her to be in the same state that I am in when I'm in pain', does single out a definite condition for the truth of ' $\mathrm{S}$ is in pain'.

\section{Peacocke on concepts of conscious states}

Christopher Peacocke has offered an account of our concepts of conscious states that directly challenges Wittgenstein's view by endorsing a version of the natural properties view and accepting the model of introspection-and-identity. ${ }^{7}$ Examining that account is a helpful way to explore the issues about natural properties and sensation concepts.

According to Peacocke, our grasp of the concept pain is 'anchored' in the first-person case: in our awareness of our own feelings of pain. At a first pass, Peacocke's proposal is that possessing the concept pain involves two things:

(i) knowing what it is like to feel pain;

(ii) having tacit knowledge that for someone else to be in pain is for them to be in the same conscious state that one is in oneself when one is in pain.

But that is only a first pass. To understand the idea of someone else being in the same conscious state that I am in when I am in pain, I must grasp the idea of someone other than myself being a subject of experience at all. And in Peacocke's view, just as my grasp of the concept pain is anchored in my knowledge of what it is like to be in pain, so my grasp of the concept conscious subject is anchored in my knowledge of what it is like to be a conscious subject. He holds, further, that the concepts conscious state and conscious subject are interdependent: a conscious state is, in its nature, a state of a conscious subject; and a conscious subject is, in its nature, a thing that has conscious states. In line with that interdependence, Peacocke's full view is that grasping the concept pain involves satisfying this more complex condition:

(i) knowing what it is like to feel pain;

(ii*) having tacit knowledge that for someone else to be in pain is (a) for them to be something of the same kind as me (a subject); and also (b) for them to be in the same state I'm in when I'm in pain. ${ }^{8}$

In what follows, I shall ignore this complication, and focus just on the simple account given by clauses (i) and (ii) above. But we should remember that Peacocke's full account is more complex.

We can note three important features of this account. First, Peacocke's idea is that one's grasp of what it is for someone else to be in pain is explained by one's grasp of what it

\footnotetext{
${ }^{6}$ Wittgenstein, Philosophical Investigations, §350.

${ }^{7}$ Christopher Peacocke, Truly Understood (Oxford: Oxford University Press, 2008), chapter 5.

${ }^{8}$ For this formulation, see Peacocke, Truly Understood, 175.
} 
W. Child - "Sensations, Natural Properties, and the Private Language Argument” - forthcoming in K. Cahill and T. Raleigh eds, Wittgenstein and Naturalism, Routledge.

is for one to be in pain oneself, together with knowledge of the identity. As I have said, Wittgenstein does not deny that, when $S$ is in pain, $S$ is in the same state that I am in when I am in pain. What he denies is that we can appeal to that identity in explaining what it is for $\mathrm{S}$ to be in pain. But that is precisely what Peacocke thinks we can do: his account deliberately and explicitly rejects this Wittgensteinian view.

Second, as Peacocke stresses, his account assumes a doctrine of natural properties. ${ }^{9}$ Mental properties, he thinks, are 'properties in their own right'; they do not need to be reduced to anything else in order to count as genuine properties. By the same token, the notion of identity of conscious state across different subjects is 'a notion in good standing' which does not require 'further elaboration, in terms of functional role' or anything else. So to grasp the idea of someone else being in the same conscious state that I am in when I am in pain, I do not need any further specification of what it takes for someone to be in the same conscious state as that. To see why Peacocke's account requires this sort of naturalism about properties, suppose that the natural properties view were false; so, considered in itself, any conscious state in someone else would have an equally good claim to be counted the same kind of conscious state as my state of pain. Then the clause, 'for S to be in pain is for S to be in the same conscious state that I am in when I am in pain', would not specify a determinate condition for the truth of ' $\mathrm{S}$ is in pain'. On the assumption that there are natural properties, however, it is at least arguable that we can appeal to a basic notion of sameness of conscious state to specify what it takes for $\mathrm{S}$ to be in pain.

Third, Peacocke claims two advantages for his account of concepts of conscious states. In the first place, it explains the uniformity of meaning between first-person and thirdperson ascriptions of pain and other conscious states. Since what it is for someone else to be in pain is explained in terms of her being in the same conscious state that I am in when I'm in pain, there is no danger that the property of pain that I ascribe to other people might be different from the property of pain that I ascribe to myself. ${ }^{10}$ By contrast:

other theories, and especially some forms of 'criterial' accounts favored by some neoWittgensteinians, have famously had difficulties in explaining how the same thing is meant in ... first-person and third-person psychological ascriptions. ${ }^{11}$

A second advantage Peacocke claims for his account is that it explains how it is possible to understand the thought that someone else is in pain without knowing what would count as evidence that she is in pain. ${ }^{12}$ He takes it as obvious that understanding third-person ascriptions of pain is independent of knowing what counts as evidence that someone else is in pain - citing with approval Rogers Albritton's observation that one might have the concept toothache yet simply have 'no notion how people with toothache [are] likely to behave, these days. ${ }^{13}$ Wittgensteinian views, Peacocke thinks, again have difficulty in accommodating that insight. position?

Is Peacocke’s account successful? Does it offer a viable alternative to Wittgenstein's

\footnotetext{
9 As Peacocke puts it, his account assumes ‘a certain irreducible realism' about properties (Truly Understood, 179; all quotations in this paragraph of the main text are taken from that page). The kind of realism about properties that Peacocke has in mind is some version of the natural properties view; that is what is needed if the appeal to the notion, 'same conscious state as this', is to do the work that he requires.

${ }^{10}$ This explains the point advertised in note 4 above: that, on an account that appeals to identity in answering our initial question 2 ('How do I understand what it is for someone else to be in pain?'), the answer to question 2 brings with it an answer to question 3 ('Is the property of pain that I ascribe to others on the basis of what they say and do the same as the property I ascribe to myself without evidence?’).

${ }^{11}$ Peacocke, Truly Understood, 165.

${ }^{12}$ Peacocke, Truly Understood, 177.

${ }^{13}$ Rogers Albritton, “On Wittgenstein's Use of the Term 'Criterion',” in Wittgenstein: The Philosophical Investigations, ed. G. Pitcher (London: Macmillan, 1968), 248.
} 
W. Child - "Sensations, Natural Properties, and the Private Language Argument” - forthcoming in K. Cahill and T. Raleigh eds, Wittgenstein and Naturalism, Routledge.

\section{Approaching the middle ground}

We have seen that Wittgenstein's rejection of natural properties plays a crucial role both in his argument against the possibility of defining sensation words by introspective ostension and in his argument against the possibility of appealing to identity to explain what it is for someone else to be in pain. So, on the face of it, someone who accepts the doctrine of natural properties has a ready way of bypassing Wittgenstein's concerns about both aspects of the model of introspection and identity. Peacocke's account of our concepts of conscious states takes exactly that route.

I shall argue, however, that the opposition between Wittgenstein's anti-platonist account of our concepts of sensations and the view of sensation-concepts that is suggested by the natural properties view is not as straightforward as it may initially seem. On the one hand, someone who takes the natural-properties view cannot avoid making some appeal to our classificatory practices in explaining our concepts of conscious states. On the other hand, the content of Wittgenstein's anti-platonism needs careful unpacking and, if it is developed in a way that preserves common-sense intuitions, there is less distance than there may initially seem to be between the Wittgensteinian account of sensation-concepts and the account we get from a plausible application of the natural properties view.

My suggestion is this. If we start with the natural properties view, we will find ourselves moving towards Wittgenstein's practice-based account of our concepts of conscious states. If we start with Wittgenstein's anti-naturalist account, we will find ourselves moving towards some form of natural properties view. I do not say that we will reach the same position whatever our starting point. But I do say that we should explore the middle ground that lies between an extreme naturalism and an extreme anti-platonism about sensation properties: the correct view surely lies somewhere in this middle ground.

\section{3.i From natural properties to classificatory practices}

Suppose we accept the metaphysics of natural properties: any set of things shares, or defines, a property; but some properties are objectively more natural than others. What impact does that view about the metaphysical status of properties have on the question, which properties our words or concepts pick out? Lewis's suggestion is this. It is possible for a word or concept to pick out a highly unnatural property: 'quus' and 'grue' are examples of that. But relatively natural properties are more eligible referents for our words than less natural properties; they are the default referents. Unless we do something to upset that default (for example, by explicitly defining a word so as to pick out a highly unnatural property), our words and concepts will pick out relatively natural properties rather than relatively unnatural properties. On this view, the naturalness of properties plays a role in determining the reference of our words. But naturalness does not determine reference all by itself; our classificatory practice plays some role, too.

One reason why practice plays an essential role in determining the reference of our word 'pain', or our concept pain, even if we accept the metaphysics of natural properties, is that someone who feels pain on an occasion has an experience that instantiates a number of different properties. Her sensation is a pain. But it is something more specific: an intense, gnawing toothache. And it is something more general: a bodily sensation. Consider an account of sensation-concepts like Peacocke's, on which my grasp of the concept pain is anchored in my singling out sensation-properties in the first-person case. What determines which particular property I do single out; what determines that my word 'pain', say, applies to pains in general, rather than being restricted to toothache? Peacocke's answer is, crudely, that I am disposed to apply my word 'pain' to any sort of pain I feel, and not just to toothache; my use of the word is as he puts it 'keyed to instances in [me] of the property of 
W. Child - "Sensations, Natural Properties, and the Private Language Argument” - forthcoming in K. Cahill and T. Raleigh eds, Wittgenstein and Naturalism, Routledge.

being a pain ${ }^{14}$ rather than instances of some more restricted property. Even given the existence of natural properties, then, the meaning of a sensation term is not established by ostension alone; classificatory practice plays a crucial role in determining which property I am picking out. ${ }^{15}$

Another reason for thinking that classificatory practice must play a role in determining the referents of our sensation-terms starts with an example from Wittgenstein:

A tribe has two concepts, akin to our 'pain'. One is applied where there is visible damage and is linked with tending, pity etc. The other is used for stomach-ache, for example, and is tied up with mockery of anyone who complains. 'But then do they really not notice the similarity?' - Do we have a single concept everywhere where there is a similarity? The question is: Is the similarity important to them? And need it be so? ${ }^{16}$

It seems clear that the people in Wittgenstein's example have legitimate concepts. Call the concept they apply to pain with visible damage pain $_{1}$ and the concept they apply to pain without visible damage pain $_{2}$. And suppose that, in the objective hierarchy of naturalness, the property of pain is the most natural property that is instantiated in the kinds of circumstance in which these people apply their concept $p a i n_{1}$ to someone. Should we say that their concept pain $_{1}$ therefore refers to pain, rather than the more restricted property, pain $_{1}$ ? If we interpret their concept that way, we must say that, when they refuse to apply their concept pain $_{1}$ in cases of pain without visible damage, they are simply wrong about the extension of the concept. But that seems highly implausible. The situation seems rather to be this. Our concept pain picks out the property of pain. The other people's concept pain 1 picks out a different property: the property of pain-with-visible-damage. And the difference between the reference of our concept and the reference of theirs is not a matter of any difference in the properties that are instantiated in people who belong to the two different communities. It is, rather, a matter of the difference between our practice of using our concept pain and their practice of using their concept pain 1 . As before, even given the existence of natural properties, which property a word or concept picks out is in part a matter of our classificatory practice. ${ }^{17}$ Once we see that point in the current case, it seems clear that our practice of applying our words in the way we do will have a crucial role in determining the reference of our concepts in very many other cases, too.

For these reasons, then, even if we accept the metaphysics of natural properties, and even if we accept that properties that are relatively natural are more eligible referents for our words than properties that are less natural, we must also accept that our classificatory practices play a vital role in determining which properties our words pick out. If we start from the natural-properties view, we are driven towards the Wittgensteinian view that what it takes for one thing to count as similar to another, or as having the same property as another, is not dictated by reality itself but depends in part on our classificatory practices.

\section{3.ii $\quad$ From classificatory practices to natural properties}

On Wittgenstein's view, I said, what it takes for one thing to count as similar to another is not determined by reality itself but depends in part on our classificatory practices: on what we

\footnotetext{
${ }^{14}$ Peacocke, Truly Understood, 189.

${ }^{15}$ For a similar stress on the role of recognitional abilities in determining which property I pick out with a sensation-concept that I introduce by introspective ostensive definition, see Brian Loar, "Phenomenal States (Second Version)”, in The Nature of Consciousness ed. Ned Block et al. (Cambridge, MA: MIT Press, 1997).

${ }^{16}$ Ludwig Wittgenstein, Remarks on the Philosophy of Psychology Volume II, ed. G. H. von Wright and H. Nyman, trans. C. Luckhardt and M. Aue (Oxford: Blackwell, 1980), §638.

17 Note the obvious similarity between this argument and Burge's argument about the way in which the reference of a term like 'arthritis' depends on the social practice of applying it in a particular way (see Tyler Burge, "Individualism and the Mental," in Midwest Studies in Philosophy IV (1979))
} 
W. Child - "Sensations, Natural Properties, and the Private Language Argument” - forthcoming in K. Cahill and T. Raleigh eds, Wittgenstein and Naturalism, Routledge.

find it natural to count as similar to what. But how exactly does similarity, or sameness of property, depend on our practices? We can distinguish two different ways of developing the basic idea. One development leads to an extreme anti-realism about properties and standards of similarity. The extreme view is certainly distinct from any version of the naturalproperties view. But it is deeply counterintuitive and it is hard to think that this is the view that Wittgenstein intends. A second way of developing the basic idea leads to a modest realism about properties. That is a plausible view in its own right, and is plausibly ascribed to Wittgenstein. But it appeals to a notion of sameness of property that cannot be spelled out in terms of our actual human capacities to classify things as being similar to, or different from, one another. So, I shall argue, even if we start from a Wittgensteinian, practice-based conception of properties, we cannot avoid accepting some element of the natural properties view.

Suppose we introduce some word by reference to a set of examples: 'The word "F" applies to this, this, and this, and to anything else that is relevantly similar to these things'. The general anti-platonist intuition is that what it takes for something to be relevantly similar to the examples is a matter of our classificatory practice. But how exactly should we understand the role of our classificatory practice in defining a standard of similarity?

The extreme view is that what it takes for a thing to be similar to the examples is determined by what we actually judge to be similar when we consider the matter and classify the thing as being $\mathrm{F}$ or not-F (or what we would judge to be similar if we were to consider it and classify it as $\mathrm{F}$ or not-F). Whether or not the application of the word ' $\mathrm{F}$ ' in a particular case is correct, then, is directly determined by what we actually say (or would say) when we consider that particular case and reach a verdict. But that is a radically revisionist view. We ordinarily think that whether some word ' $F$ ' applies to an object depends on two things: the meaning that we have given to the word; and the way the object is. It does not depend on what we would in fact say if we were to consider the question and reach a verdict about whether or not the object is F. On the contrary, we think, when we do consider an object and judge that it is F, our judgement is true or false in virtue of whether or not the object meets the standard of F-ness that we have already laid down. But the current view explicitly rejects that common-sense thought. Similarly, we ordinarily think that the standards of similarity and correctness associated with our words and concepts extend to new cases in a way that is not restricted by our actual capacity to apply them. Our actual human capacities are limited: there are calculations that are too large or complex for us to be able to complete; objects that are too small or inaccessible for us to be able to observe and classify; environments that are too hostile for us to be able to investigate. But, we think, the standards of similarity and correctness that we establish in connection with cases that we are able to calculate or classify apply determinately to these other cases. There is, we think, a fact of the matter about the correct result of applying our mathematical operations to a new case, even if it exceeds our calculative capacities; there is a fact of the matter about whether some object that is too small or inaccessible for us to classify is in fact similar to other things by our standards of similarity; and so on. But, as before, the extreme view rejects that ordinary thought. If what counts as similar to what is determined by what we actually classify (or would classify) as similar, our standards of similarity simply do not extend to cases that transcend our classificatory capacities. That is a possible view. And it is a view that some interpreters have ascribed to Wittgenstein. ${ }^{18}$ But it involves the wholesale rejection of basic elements of our

\footnotetext{
18 See e.g. Michael Dummett, "Wittgenstein on Necessity: Some Reflections,” in his The Seas of Language (Oxford: Oxford University Press, 1994). Dummett ascribes to Wittgenstein the view that 'it is only our doing [a] calculation and "putting it in the archives" that constitutes its result as being that obtained by doing it correctly; so, if we never do that calculation, there is no one correct result' (Dummett, "Wittgenstein on Necessity”, 459). The view that Dummett attributes to Wittgenstein is even more radical than the position
} 
W. Child - "Sensations, Natural Properties, and the Private Language Argument” - forthcoming in K. Cahill and T. Raleigh eds, Wittgenstein and Naturalism, Routledge.

ordinary thought. If that is the view that Wittgenstein intends, then his image of himself as a philosopher who leaves everything as it is seems radically mistaken.

That is one way of understanding the basic anti-platonist intuition that what it takes for one thing to be similar to another is a matter of our classificatory practices. The alternative way of understanding the basic intuition shares the idea that there are numerous different possible standards of similarity that are consistent with an initial set of examples. It shares the idea that no one of these possible standards of similarity is objectively the correct one, or objectively 'straighter' or more natural than any other. And it shares the idea that what ties a word or concept to a particular standard of similarity is that that is the standard embodied in the way we find it natural to classify things. But, on the modest view, once we have done enough to single out a particular property by classifying things as similar to, or different from, one another in the way we do, there is simply a fact of the matter about whether or not something has that property: a fact of the matter that is not determined by how we actually classify it when we come to consider the matter (or how we would classify it if we were to consider the matter). Our classificatory practices play a crucial role in establishing standards of correctness for our words and concepts. But the standards we establish are not limited by our own actual ability to apply them; there are facts of the matter about how our concepts apply to things in cases to which we ourselves are unable to apply them.

It seems fair to say that this modest realism has something in common with the natural properties view, insofar as it involves a view of the naturalness or sameness of properties on which what it takes for one thing to have the same property as another is not limited by our actual human capacities to tell whether or not they have the same property. The modest realist insists, for instance, that there is a fact of the matter about whether some object that is too small or inaccessible for us to examine has the same property that we attribute to objects that we can examine and categorize. But what does it take for this small or inaccessible object to have the same property as the property that we identify in objects that we can examine? It cannot be that we actually classify it (or would classify it) as having the same property; for, in the nature of the case, our classificatory capacities do not extend to the object in question. The modest realist's view must be that, once we have singled out a property through our classificatory practice in cases we can consider, there is simply a fact of the matter about what it is for a tiny or inaccessible object to have the same property as that. And that use of the notion of sameness of property, as I have said, has something significant in common with the natural properties view. The picture is one in which, in picking out the properties we do, we latch onto properties that are there anyway: properties whose status as genuine properties does not depend on us, our concepts, or our practices of classification. That is what allows us to single out properties in a way that extends beyond our own ability to identify instances.

\section{4. $\quad$ Defending the middle ground.}

I have argued that an adequate account of our concepts of conscious states must occupy a middle ground, which gives a role in determining the content of those concepts both to our actual classificatory practices and to a notion of naturalness or sameness of properties that cannot be understood simply in terms of what we do in fact find it natural to classify as similar to what. And I have suggested that Wittgenstein's view has just that form. But does

discussed in the text, since it rules out any appeal to subjunctives about the results we would get if we were to do a calculation that no-one ever actually performs. 
W. Child - "Sensations, Natural Properties, and the Private Language Argument” - forthcoming in K. Cahill and T. Raleigh eds, Wittgenstein and Naturalism, Routledge.

this middle ground really exist? We can approach that question by considering Peacocke's critique of a 'neo-Wittgensteinian' view.

Recall that, on Peacocke's view of the concept pain, what comes first in the order of explanation is the property of pain. The account appeals to that property at two stages: first, in explaining our grasp of the concept pain in the first-person case; and then in explaining how we understand ascriptions of pain to other people. Now Peacocke anticipates a neoWittgensteinian objecting to his account on the grounds that 'there simply is no property of being in pain that has all the characteristics needed by [Peacocke's] account' ${ }^{19}$ 'Under this response', he says, 'it is legitimate to speak of the property of being in pain, but this property of a mental event must be regarded as a construct out of human conceptual reactions and expressive capacities, in a way that is incompatible with its being causally and rationally explanatory of thinkers' first-person judgements that they are in pain' ${ }^{20}$. Peacocke argues that this neo-Wittgensteinian view is inadequate. He faces it with a dilemma. Suppose, first, that we treat the property of pain 'as a construct out of human conceptual reactions and expressive dispositions'. In that case, our account will fail to make sense of the range of applications of the concept pain that we actually take to be intelligible. We can, for instance, understand the thought that octopuses, dolphins, and whales feel pain. But such creatures have no 'distinctively human reactions and expressive dispositions'. So if we understand the property of being in pain as a construct out of such reactions and dispositions, we cannot understand the thought that these creatures feel pain. In response to that horn of the dilemma, the neo-Wittgensteinian may offer a different view, saying that 'a role in human conceptual and expressive life' plays an essential role in singling out the property of pain - in fixing the reference of the concept pain - but that 'the very same conscious property could be instantiated by creatures for which it does not have that role'. But, Peacocke objects, if the neo-Wittgensteinian takes that view, the position collapses into a version of Peacocke's own account. For 'if there is such a real conscious property that has a nature independently of human conceptual reactions and expressions, then it can play a role in making first-person judgements rational', and it can play a role in explaining how we can understand third-person ascriptions of pain without knowing what would count as evidence that they were true. And that is just the view that Peacocke is promoting.

Care is needed in assessing Peacocke's objection to the 'neo-Wittgensteinian' view, for two reasons. On the one hand, as we saw in 3.i, Peacocke's own account itself gives some role to our classificatory practices in specifying exactly which property it is that a person picks out in the first-person case, because it gives a role to her disposition to apply the word 'pain' to all pains she feels, and not simply to a wider, or a more restricted, set of feelings. So Peacocke's own view is not the most uncompromising application of the natural-properties view. On the other hand, as we saw in 3.ii, the idea that the property of pain is an artefact or 'construct' of our classificatory practices can be developed in different ways: developed one way, it involves a radical anti-realism; developed in another way, it leads to a modest form of realism. I will proceed by considering the effectiveness of Peacocke's complaint considered as an argument against the kind of modest realism about properties that I described in section 3.ii. It may be that that is not exactly the kind of neoWittgensteinian view that Peacocke has in mind. Since, however, he suggests that every form of neo-Wittgensteinianism about properties will be vulnerable to versions of the objections he raises, our discussion will certainly be relevant to assessing his argument.

\footnotetext{
19 Peacocke reports that this objection was suggested to him by Crispin Wright. The objection is closely related to the points I made in section 3.i above.

20 Peacocke, Truly Understood, 190. Subsequent quotations in this paragraph of the text are taken from pp. 190-1 of Peacocke's book.
} 
W. Child - "Sensations, Natural Properties, and the Private Language Argument” - forthcoming in K. Cahill and T. Raleigh eds, Wittgenstein and Naturalism, Routledge.

The first horn of Peacocke's dilemma is that, if the neo-Wittgensteinian presses the idea that pain is a 'construct out of human conceptual reactions and expressive dispositions', she will be unable to make sense of ascriptions of pain to certain non-human animals, ascriptions that obviously do make sense. But that criticism seems ineffective against the position I have outlined. Nothing in Wittgenstein's position requires that a state of some other mammal only qualifies as a pain if the creature itself has human-style conceptual reactions to pain or expresses pain in exactly the ways that human beings express it. What matters for the intelligibility of ascribing pain and other experiences to creatures of some kind is whether the states in question play a role in the creatures' lives that is sufficiently similar to the role that pain plays in our lives. And a state of a whale or a dolphin can meet that standard without the creature needing to have concepts or specifically human interests, and without the creature behaving in exactly the ways that humans do. So Wittgenstein's view does make room for understanding ascriptions of pain and other sensations to non-human animals whose lives and behavior are very different from ours. It is plausible that, when we move beyond the simple case of pain, we will quickly reach cases where, on Wittgenstein's approach, the concepts we apply to human beings will not be straightforwardly applicable to creatures that lack the dispositions and conceptual capacities that we humans possess. It is hard to see how to make sense of ascriptions of hope or grief, for instance, to creatures whose interests, capacities, and reactions are radically different from the kinds of interests, capacities, and reactions that we have. ${ }^{21}$ But that is as it should be: it really is unclear that we can make sense of a whale, a cat, or a sheep experiencing grief, envy, hatred, and so on.

So much for the first horn of the dilemma that Peacocke poses for a neoWittgensteinian view. What of the second horn: the argument that, if we regard human reactions to, and expressions of, pain simply as singling out a property of pain that can play a role in causally explaining self-ascriptions of pain, and in making sense of ascriptions of pain in cases where we have no idea what would count as evidence for the presence of pain, then our position collapses into Peacocke's version of the natural properties view?

In the first place, there is no reason why a Wittgenstein view of pain cannot accept that the judgement 'I am in pain' is a causal response to pain. It is an obvious, commonsense truth that we ascribe pain to infants long before they exhibit any linguistic or conceptual reactions to pain. Equally obviously, an infant's being in pain stands in causal relations to other events and states of affairs. It is caused by physical impacts and injuries. It causally affects the child's future behavior: the burned child avoids the flame because getting burned was painful. And it causally affects other people's behavior; we treat the child with sympathy and concern because she is in pain. I see nothing in Wittgenstein that conflicts with these common-sense truths. Now consider what happens when the child learns to apply the word 'pain' to herself. We teach the child to judge 'I'm in pain' in circumstances where we already know, on independent grounds, that she is in pain; in doing so, we are teaching her to respond to her pain by judging that she is in pain. Once the teaching has succeeded, the response of judging 'I'm in pain' is, as Peacocke puts it, 'keyed to' the occurrence of pain in the child. There is no reason for a Wittgensteinian to deny that, when the child judges 'I'm in pain', she makes that judgement because she is in pain. And there is no reason for her to deny that that is a causal because; the child's judging 'I'm in pain' is causally explained by her being in pain.

But recognizing that our self-ascriptions of sensations are causally responsive to the sensations we self-ascribe does not undermine the Wittgensteinian idea that our classificatory practices play an essential role in determining which properties we pick out. Recall

21 For brief comments on the cases of hope and grief, see Wittgenstein, Philosophical Investigations, part II $\S \S 1-2$. 
W. Child - "Sensations, Natural Properties, and the Private Language Argument” - forthcoming in K. Cahill and T. Raleigh eds, Wittgenstein and Naturalism, Routledge.

Wittgenstein's example of the people who have two concepts - pain ${ }_{1}$ and pain $_{2}$ - where we have the single concept pain. The reference of these people's terms 'pain ${ }_{1}$ ' and 'pain 2 ' is not fixed merely by the nature of the properties instantiated in this community. What determines the reference of the terms is in part their actual classificatory practice. But that is completely compatible with the point that self-ascriptions are causally responsive to occurrences of the properties that are thereby self-ascribed. In Wittgenstein's imagined community, selfascriptions of the form 'I'm in pain ${ }_{1}$ ' are by and large causally explained by the presence of instances of pain ${ }_{1}$; self-ascriptions of the form 'I'm in pain ${ }_{2}$ ' are by and large causally explained by the presence of pain .

In the second place, I have already argued that the Wittgensteinian view, as I have characterized it, can accommodate the fact that we can understand third-person ascriptions of pain in cases where we have no idea what would count as evidence that someone else is in pain. Our classificatory practice has an essential role to play in determining which property we are picking out; but once we have singled out that property, we can go on to make sense of ascriptions of the same property in cases that transcend our actual human capacity to tell whether or not something has the property. So I think Peacocke is wrong to suggest that if we take that view of properties then we have given up a neo-Wittgensteinian position and have instead adopted his own view.

It might be suggested that my disagreement with Peacocke about the prospects for a Wittgensteinian view is a purely verbal one. On the one hand, it might be claimed, my allegedly Wittgensteinian form of modest realism is not a distinctively Wittgensteinian position at all but is, rather, a version of the kind of realism about properties that Peacocke himself recommends. On the other hand, it may be suggested, what Peacocke means by a 'neo-Wittgensteinian' position is what I have described as extreme anti-realism about properties: the kind of view on which what it is for $x$ to belong to the same kind as $y$ can be understood only in terms of how we find it natural to classify $x$ when we actually consider the case (or how we would find it natural to classify $x$ if we were to consider the case). So, the suggestion goes, I am not in the end opposing Peacocke's view that there are really only two kinds of position available: an unacceptable anti-realism or constructivism about properties; and a sensible form of realism. The difference is only over where to locate Wittgensteinian views in this dichotomy: I think Wittgenstein's views lead us to the modest realist position; Peacocke thinks they lead us to the unacceptably anti-realist position. Settling that disagreement is of course important for the interpretation and assessment of Wittgenstein's views. But, on this line of thought, there is no substantive philosophical disagreement between me and Peacocke.

This irenic conclusion seems premature, however. I agree that Peacocke and I are maneuvering in the same general area. We both reject the extreme anti-realist or constructivist view of properties. And we both reject the most radical alternative, on which the naturalness of properties determines which properties our words and concepts pick out all by itself, with no contribution at all from our classificatory practice. But, as I said in 3.i, Peacocke's position seems to me to give insufficient recognition to the role of our actual classificatory practices in determining which properties our concepts of pain and other conscious states pick out. Different linguistic communities may employ concepts that pick out different properties, even if there are no differences in the properties that are actually instantiated in those communities' environments. We cannot make sense of these differences in properties picked out unless we recognize that our classificatory practice plays a larger role than Peacocke allows in defining or specifying what counts as sameness of property.

$\underline{5 .}$ Conclusion 
W. Child - "Sensations, Natural Properties, and the Private Language Argument” - forthcoming in K. Cahill and T. Raleigh eds, Wittgenstein and Naturalism, Routledge.

I suggested at the start of 3.i that, if our account of concepts of conscious states starts from a commitment to natural properties, we are bound to recognize on reflection that there is a role for our actual classificatory practices in determining which properties our concepts pick out. On the other hand, if we start from the anti-platonist idea that the notions of similarity or sameness of property must be understood in terms of our classificatory practice, we are bound to recognize that we also need a notion of sameness of property that extends beyond our limited capacity to apply our own concepts and categories.

I have argued for three conclusions. First, that the suggestion just outlined is correct: an account of our concepts of conscious states must, as I have put it, occupy the middle ground that gives a role both to our classificatory practices and to a notion of sameness or naturalness that extends beyond our limited capacities to recognize similarity or sameness of property. Second, that Wittgenstein's own view is a position of that general kind: in the terms of 3.ii, he advances a version of modest realism. Third, that Peacocke's objection to neo-Wittgensteinian views is unsuccessful. No doubt there is room for refinement and expansion of these conclusions. But the correctness of these general conclusions - both about the location of the right position in this debate and about the form of Wittgenstein's view - seems clear. ${ }^{22}$

\footnotetext{
${ }^{22}$ An earlier version of this paper was presented at the conference, 'Wittgenstein, Philosophy of Mind, and Naturalism', at the University of Bergen in June 2015. I am grateful to the participants in that conference, and especially to the organizers, Kevin Cahill and Thomas Raleigh, for very helpful comments and discussion.
} 